- Mark Herrmann, director of the $\mathrm{Z}$ machine and the pulsed-power science centre at Sandia. "We look at it as confirmation that it is working like we think it should."

The experiment yielded about $10^{10}$ highenergy neutrons, a measure of the number of fusion reactions achieved. This is a record for MagLIF, although it still falls well short of ignition. Nevertheless, the test demonstrates the appeal of such pulsed-power approaches to fusion. "A substantial gain is more likely to be achieved at an early date with pulsed power," says nuclear physicist David Hammer of Cornell University in Ithaca, New York, who co-wrote a 2013 US National Research Council assessment of approaches to fusion energy.

With its relatively slim US $\$ 5$-million annual budget, MagLIF is a David next to two fusion Goliaths: the \$3.5-billion National Ignition Facility (NIF) at Lawrence Livermore National Laboratory in California, and the $€ 15$-billion (US\$20-billion) ITER experiment under construction in France. (Sandia has about $\$ 80$ million to operate the $\mathrm{Z}$ machine each year, but it serves other experiments in addition to MagLIF.) The NIF squashes fuel capsules using nearly 2 megajoules of laser energy, and ITER will use 10,000 tonnes of superconducting magnets in a doughnut-shaped 'tokamak' to hold a plasma in place to coax self-sustaining fusion.

Both of the big projects have run into problems. After a concerted two-year effort, NIF fell well short of achieving ignition by a 2012 deadline. Its fusion yields have since increased

\section{FEELING THE PINCH}

Magnetized Liner Inertial Fusion uses a heating laser, a stabilizing magnetic field and a force called a Z pinch to implode a cylinder of hydrogen fuel.

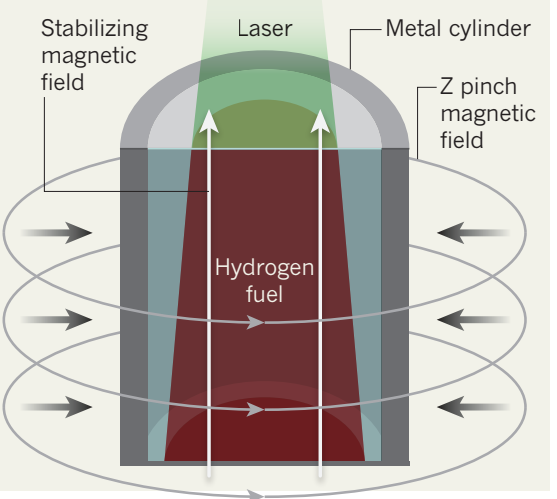

markedly - nearly $10^{16}$ neutrons were created in a recent shot, Herrmann says - but the more than \$300-million-a-year programme faces further budget cuts in 2014. Meanwhile, delays and budget overruns have become the norm at ITER. The facility is not expected to begin operations until $2027-11$ years later than initially planned.

In addition to being cheaper, MagLIF seems to have technical advantages. The laser not only preheats the hydrogen fuel, but also makes it more conductive - and thereby more susceptible to the Z pinch. Furthermore, in a paper published late last year, MagLIF physicists showed evidence suggesting that the applied secondary magnetic field, as well as insulating the fuel, may have the happy side effect of stabilizing the cylinder as it implodes (T. J. Awe et al. Phys. Rev. Lett. 111, 235005; 2013). If so, that would cut down on hydrodynamic instabilities, which can disperse the energy and fuel before fusion can get going, says Stephen Slutz, a Sandia physicist who proposed the MagLIF system in 2009.

In the next few years, MagLIF scientists plan to turn up all three dials at their disposal. They can boost the $\mathrm{Z}$ machine to up to 27 million amperes; they can ramp up the magnetic field to as high as 30 tesla; and they plan to upgrade the laser to 8 kilojoules. They also aim to switch from fuel made of the hydrogen isotope deuterium to fuel containing both deuterium and another isotope, tritium - which should also lift yields. By 2015, they hope to achieve a yield of $10^{16}$ neutrons, or about 100 kilojoules enough to show that ignition is within reach.

It could be crucial to make progress quickly. The US National Nuclear Security Administration, the division of the Department of Energy that funds the NIF, the $\mathrm{Z}$ machine and other laser fusion efforts, plans to deliver an assessment to Congress in 2015 about the future of these technologies. If MagLIF hits its 100-kilojoule goal, it could bolster an argument for upgrading the $\mathrm{Z}$ machine to 60 million amperes or more, which simulations suggest would be sufficient to reach ignition.

"We're all hoping that they will, in fact, find success with their early shots to justify the construction of a larger machine," says Hammer.

\title{
Water risk as world warms
}

\section{First comprehensive global-impact project shows that water scarcity is a major worry.}

\section{BY QUIRIN SCHIERMEIER}

$\mathrm{W}$ Then pondering the best way to study the impact of climate change, researcher Hans Joachim Schellnhuber liked to recall an old Hindu fable. Six men, all blind but thirsty for knowledge, examine an elephant. One fumbles the pachyderm's sturdy side, while others grasp at its tusk, trunk, knee, ear or tail. In the end, all are completely misled as to the nature of the beast.

The analogy worked. Although many researchers had modelled various aspects of the global-warming elephant, there had been no comprehensive assessment of what warming will really mean for human societies and vital natural resources. But that changed last year when Schellnhuber, director of the Potsdam Institute for Climate Impact Research in Germany, and other leading climate-impact researchers launched the Inter-Sectoral Impact Model Intercomparison Project. This aims to produce a set of harmonized global-impact reports based on the same set of climate data, which will for the first time allow models to be directly compared. Last month it published its initial results in four reports in Proceedings of the National Academy "We are facing
problems
that result
in domestic
instability and
migration." of Sciences ${ }^{1-4}$. These suggest that even modest climate change might drastically affect the living conditions of billions of people, whether through water scarcity, crop shortages or extremes of weather.

The group warns that water is the biggest worry. If the world warms by just $2{ }^{\circ} \mathrm{C}$ above the present level, which now seems all but unavoidable by 2100 , up to one-fifth of the global population could suffer severe shortages.

"Water and all that relies on it, from food to sanitation and public health, is an emblematic aspect of climate change whose urgency people tend to instantly understand," says Schellnhuber.

To assess what a warmer world might mean for the human race, 30 groups from 12 countries have run thousands of simulations, using a standardized set of scenarios for greenhousegas emissions. They made projections of future water availability from a set of global hydrological models in conjunction with five state-of-theart climate models ${ }^{1}$ that combined projections of changes in temperature and precipitation with data on variables such as regional water cycles, river run-off and population.

The multi-model assessment suggests that, in vulnerable regions, climate change will significantly add to the problem of water scarcity 
of that is already arising from population growth. The modellers found that climate-driven changes in evaporation, precipitation and runoff will result in a $40 \%$ increase in the number of people worldwide who must make do with 崖 less than 500 cubic metres of water per year - a commonly used threshold to signify 'absolute' water scarcity.

The spread between individual models was large - some suggested that global exposure to water scarcity will double; others predicted only modest change. But no matter what the spread, the greatest effects were seen between the present-day climate and a $2^{\circ} \mathrm{C}$ warmer world.

Despite the ambiguities, the exercise will make climate-risk analysis substantially more robust, says Johan Rockström, an expert on water resources at the University of Stockholm and director of the Stockholm Resilience Centre, who was not involved in the project.

"Impact models will never be able to provide the level of detail that ultimately matters for making a city or coastline climate-proof," he says. "But they do serve as a first approximation to the severe problems deficient regions and nations are facing."

Regions most at risk from water scarcity include parts of the southern United States, the Mediterranean and the Middle East. By contrast, India, tropical Africa and high latitudes in the Northern Hemisphere can expect to receive more water in a warming world.

The projected changes in water availability have knock-on effects in other areas that rely on water. The group that modelled the response of crops to climate change found negative impacts on yields of major crops in many agricultural regions ${ }^{2}$.

In addition, drought conditions are likely to become more frequent and severe in some parts

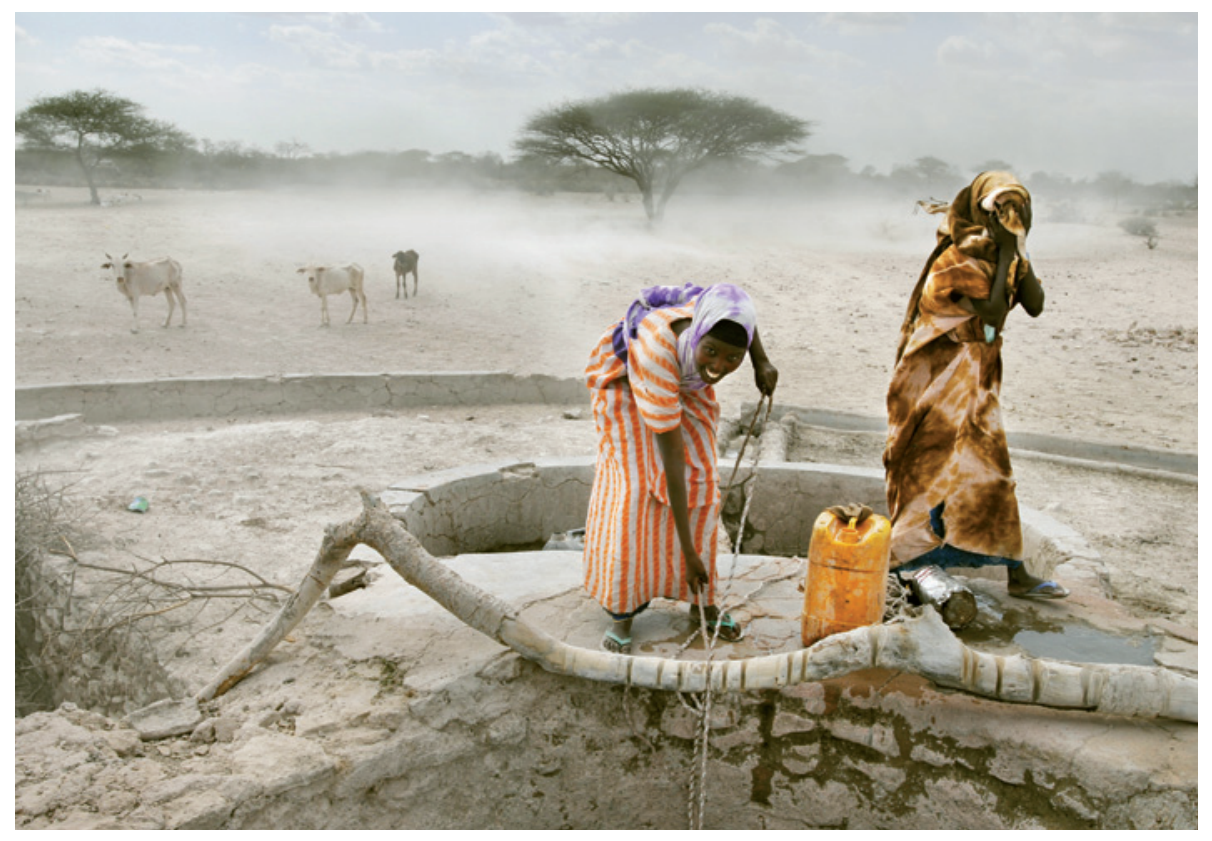

Water scarcity in parts of Africa could become worse, according to a complementary set of climate projections.

of South America, western and central Europe, central Africa and Australia, another project team reports ${ }^{3}$. Flood risk is less clear-cut, but river-flow simulations from global hydrology and land-surface models did show an increase in flood hazard in more than half of the world ${ }^{4}$.

Despite their uncertainty, the findings are " $\mathrm{a}$ stark reminder" that even moderate warming has the potential to cause severe natural, social and economic disruptions, says Rockström. "We are facing problems that result in domestic instability and migration." Rethinking international trade with a view to giving the most needy nations better access to the global food market will be essential, he says.
Uncertainty, adds Schellnhuber, is no excuse for inaction. "Those who might say, 'Come back when you've narrowed down the risk' should be reminded that climate change is a treacherous gamble," he says. "We don't quite know the odds, but the chance of losing heavily might be a lot bigger than many tend to think."

1. Schewe, J. et al. Proc. Natl Acad. Sci. USA http:// dx.doi.org/10.1073/pnas.1222460110 (2013)

2. Rosenzweig, C. et al. Proc. Natl Acad. Sci. USA http:// dx.doi.org/10.1073/pnas.1222463110 (2013).

3. Prudhomme, C. et al. Proc. Natl Acad. Sci. USA http://dx.doi.org/10.1073/pnas.1222473110 (2013).

4. Dankers, R. et al. Proc. Natl Acad. Sci. USA http:// dx.doi.org/10.1073/pnas.1302078110 (2013).

\section{$\mathrm{X}$-ray source left without home}

\section{No plans to build next-generation accelerator despite large investment by US agency.}

\section{BY EUGENIE SAMUEL REICH}

A ccelerator physicists have a vision: an energy-efficient X-ray source that can make high-resolution movies of molecules in chemical reactions. And the US National Science Foundation (NSF) has backed the dream - since 2005, it has invested more than US\$50 million to develop such a source, most likely beneath the campus of Cornell University in Ithaca, New York.

But there is one big problem: despite the inflow of cash, no US government agency has any plans to build the machine.

The source, called an energy recovery linear accelerator (ERL), would be a hybrid of a synchrotron, in which electrons emit $\mathrm{X}$-rays while whirling around a ring, and a free-electron laser, in which straight beams of electrons are induced to produce bright pulses of X-ray light.

The Cornell project is currently receiving $\$ 27$ million in a single award from the NSF's materials division - by far the division's largest grant for instrument development. But in July, the ERL concept was ranked the lowest of three potential next-generation X-ray sources by an advisory panel to the US Department of Energy. And in December, officials at the NSF told Nature that the agency has no plans to move forward with construction.

Despite all this, Thomas Rieker, the NSF programme manager for the ERL materials grant, says that the research effort has been a success, providing component designs that would allow an accelerator to be built quickly. "We wanted to keep our options open," he says. "That was the impetus for funding it."

An NSF advisory panel had strongly recommended in 2008 that the NSF invest in an ERL. So why the turnaround? Agency officials now say that the NSF's priorities and the budgetary climate have changed, and that a machine costing upwards of $\$ 1$ billion would not be a good use of taxpayers' money. 